\title{
Program Pelatihan CAD “SOLIDWORKS” Bagi Guru SMK N 2 Payakumbuh Sebagai Upaya Peningkatan Kompetensi dan Daya Saing SMK Daerah di Tingkat Nasional
}

\author{
Wanda Afnison ${ }^{*}$, Erzeddin Alwi ${ }^{2}$ \\ ${ }^{12}$ Teknik Otomotif/ Fakultas Teknik/ Universitas Negeri Padang \\ ${ }^{*}$ Corresponding author, $\supseteqq$, wandaafnison@ft.unp.ac.id
}

Revisi 30/10/2019
Diterima 30/11/2019
Publish 10/01/2020

Kata kunci:

Solidworks,

Kompetensi, Aplikasi

\begin{abstract}
Abstrak
Program pelatihan CAD (Computer Aided Design) "SOLIDWORKS" merupakan salah satu wujud transfer transfer of knowledge yang dilakukan untuk mengakselerasi peningkatan kompetensi guru SMK daerah yang mesih minim kesempatan untuk mendapatkan pelatihan/up-grade skill(Erzeddin Alwi, Nuzul Hidayat, Wanda Afnison, 2018) dari institusi diluar sekolah. Solidworks merupakan salah satu aplikasi CAD yang banyak digunakan industry manufaktur dan otomotif dalam hal perancangan produk. Program pelatihan ini diberikan kepada guru SMK Jurusan Teknik Mesin dan Teknik Otomotif di SMK N 2 Payakumbuh. Pelatihan dilaksanakan selama 4 hari tatap muka (setara 32 jam) ditambah dengan proses bimbingan daring selama 1 bulan berikutnya. Pelatihan dimulai dengan pre test di awal kegiatan untuk memetakan kemampuan guru dalam menggunakan aplikasi, dari hasil evaluasi awal terlihat masih rendahnya pemahaman guru terkait aplikasi Solidworks. Proses selanjutnya adalah materi pelatihan yang meliputi: sketch, part dan assembly. Pada akhir kegiatan peserta diberikan tugas sebuah final project. Dari hasil final project terlihat peningkatan kompetensi peserta, dimana rata-rata peserta mampu menerapkan materi pelatihan yang diberikan untuk merancang komponen otomotif. Di akhir kegiatan tim PKM dan peserta sepakat untuk membuat sebuah groub WA untuk berdiskusi seputar aplikasi Solidworks, hal ini dilakukan agar materi pelatihan dapat terus diulang dan di implementasikan dalam PBM di sekolah.
\end{abstract}

\section{PENDAHULUAN}

Analisis Situasi

SMK N 2 Payakumbuh merupakan salah satu SMK tertua di Sumatera Barat. Berdirinya SMK N 2 Payakumbuh menjadi salah satu wujud upaya pemerataan pendidikan di seluruh Indonesia yang dilakukan pemerintah. Untuk regional Sumatera Barat, kiprah SMK N 2 
Payakumbuh cukup bisa diperhitungkan. SMK N 2 Payakumbuh sering mengirimkan siswanya mewakili Sumatera Barat dalam ajang Lomba Keteampilan Siswa (LKS) tingkat nasional. Meskipun demikian jika dibandingkan dengan SMK Negeri di pulau jawa, SMK N 2 Payakumbuh pada khususnya belum mampu berbicara banyak. Langkah mereka sering terhenti jelang 5 besar kontestan terbaik. Ini juga terlihat dari capaian rangking perolehan medali SMK di Sumatera Barat pada ajang Lomba Keterampilan Siswa (LKS), dimana provinsi Sumatera Barat tidak mampu menembus angka 10 besar se Indonesia dalam 5 tahun terakhir ${ }^{[1]}$.

Dari hasil survey tim PKM ke SMK N 2 Payakumbuh yang notabenenya pernah menjadi salah satu Sekolah Berstandar Internasional (SBI). Drs Dalius menuturkan kendala yang sering mereka hadapi terkait persiapan ajang Lomba Keterampilan Siswa (LKS) adalah lambannya serapan teknologi, terutama terkait penggunaan software. Seringkali SMK di daerah mengikuti LKS tanpa persiapan yang matang. Kondisi ini beliau sampaikan berdasarkan laporan guru pembimbing LKS yang merasa sangat membutuhkan pembinaan dan peningkatan kompetensi penggunaan software agar kualitas siswa untuk mengikuti lomba LKS dapat ditingkatkan lagi. Kondisi ini terjadi lantaran kesempatan guru untuk mendapatkan training/pelatihan yang masih sangat terbatas. Berikut diskusi tim PKM bersama Kepala Sekolah yang didampingi oleh Waka Kurikulum dan salah satu guru pembimbing LKS SMK N 2 Payakumbuh.

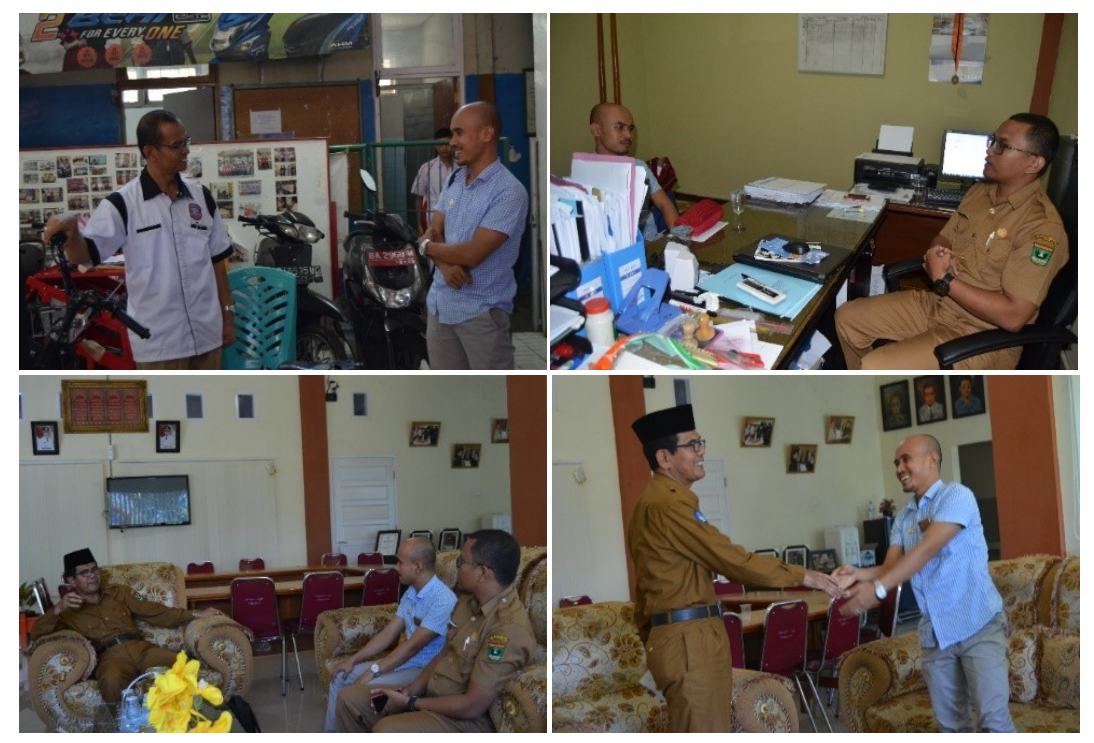

Gambar 1.Kegiatan survey lokasi ke SMK N 2 Payakumbuh

Setelah diskusi ringan dengan Drs. Dalius, Tim PKM diajak berkeliling ke labor computer SMK N 2 Payakumbuh untuk melihat ketersedian peralatan praktik. Benar saja, computer dan software yang digunakan dalam menggambar (CAD) cenderung tidak up to date. Dalam mata pelajaran gambar teknik, software desain gambar yang digunakan adalah autocad versi 2007, 12 tahun tertinggal dibanding versi terbaru 2019 yang sudah dilengkapi fitur simulasi desain. Kondisi yang sangat tidak baik tentunya ketika sekolah tidak mampu mengikuti perkembangan teknologi yang ada. Keterbatasan akses informasi dan minimnya pengembangan kompetensi guru terkait software gambar yang digunakan disinyalir menjadi factor utama permasalahan ini. Berikut dokumentasi saat Tim PKM berkunjung ke labor computer SMK N 2 Payakumbuh:
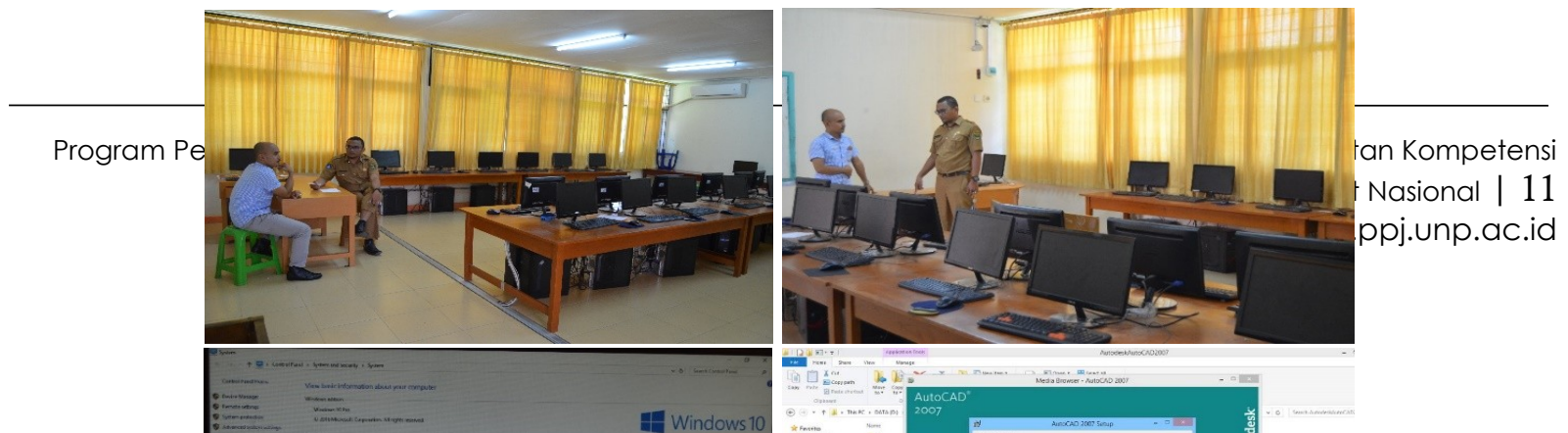


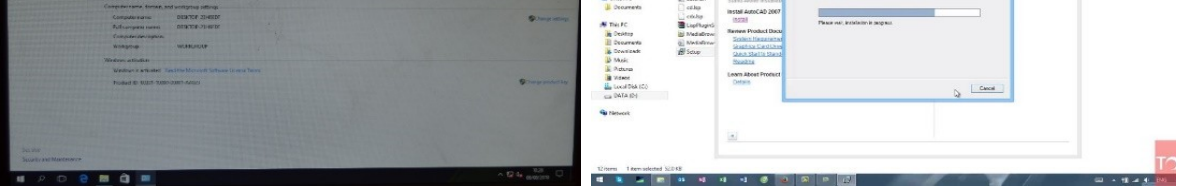

Suluah Bendang: Jurnal Ilmiah Pengabdian Kepada Masyarakat

Vol.20, No.1, 2020

Wanda Afnison, Erzeddin Alwi

Gambar 2. Kondisi labor SMK N 2 Payakumbuh

Beberapa permasalahan terkait transfer of knowledge dan up-date teknologi diatas menjadi dasar bagi Tim PKM mengajukan pengabdian masyarakat. Tim PKM memilih menggunakan software Solidworks dalam materi pelatihan karena dalam perkembangannya, software ini merupakan software yang paling banyak digunakan industry dalam melakukan desain dan perancangan produk pada $2015^{[3]}$, mengalahkan software autocad yang 12 tahun lebih dulu beredar. Kelebihan software ini adalah konsepnya yang easy to use dan menawarkan banyak fitur desain/perancangan. Selain itu software ini juga dilengkapi berbagai fitur simulasi motion, mechanical, electrical, flow simulation dll. Diharapkan dengan adanya pelatihan ini dapat meningkatkan kompetensi guru dalam mengajar dan mampu meningkatkan kualitas lulusan SMK serta peningkatan daya saing lulusan dalam mencari pekerjaan setelah lulus.

\section{Solusi Dan Target}

Dari empat poin identifikasi permasalahan di SMK N 1 Kec. Luak maka dapat dirumuskan empat solusi sbb:

1. Pada Program Kemitraan Masyarakat (PKM) ini yang menjadi fokus utama adalah transfer of knowledge teknologi terbaru otomotif. Ini merupakan salah satu permasalahan utama pada sekolah mitra. Pada kegiatan ini akan diberikan pelatihan tentang teknologi terbaru mobil dengan system Electronic Fuel Injection (EFI), penggunaan scan tool untuk identifikasi kerusakan, pemberian materi tentang teknologi ABS dan teknologi terbaru otomotif lainnya.

2. Melaui kegiatan Program Kemitraan Masyarakat (PKM), siswa akan mendapatkan hal baru dalam kemajuan teknologi otomotif. Tidak hanya sampai disana siswa juga dapat mempraktekannya langsung pada sesi kegiatan praktikum. Sehingga dapat dipastikan kegiatan ini mampu meng Up-date pengetahuan/kompetensi siswa.

3. Pada kegiatan ini juga akan dibekali dengan penggunaan alat ukur digital. Ini menjadi wajib karena hampir seluruh sistem pada mobil terbaru menggunakan alat ukur digital sebagai pendeteksi kerusakan dan peformanya. Jadi dapat dipastikan tanpa pengetahuan penggunaan peralatan ukur digital siswa tidak bisa berbuat banyak dalam menyelesaikan permasalahan pada kendaraan

4. Selama berlangsungnya kegiatan Program Kemitraan Masyarakat (PKM), siswa diberikan panduan berupa materi pelatihan dan job sheet dalam bekerja. Sehingga setiap detail proses pekerjaan dapat dilakukan dengan baik dan terukur 


\section{METODE PELAKSANAAN}

Untuk mendapatkan hasil yang optimal dari kegiatan ini, pengusul merancang tahapan kegiatan PKM meliputi: pre test(Hidayat, Arif, Setiawan, \& Afnison, 2018), teori, praktikum dan diakhiri dengan evaluasi. Berikut detail masing-masing proses:

1. Pre Test

Tahapan awal yang dilakukan adalah Pre Test. Pada tahap ini pengusul melakukan pemetaan kemampuan peserta terhadap materi yang akan diberikan. Data ini dijadikan acuan untuk materi dan metode pelatihan yang akan diberikan.

2. Pembekalan konsep teori system bahan bakar injeksi (EFI).

Pada sesi ini peserta diarahkan ke dalam kelas (teori). Kegiatan ini akan di isi dengan materi tentang perkembangan dan kemajuan teknologi terbaru sepeda motor. Pemateri akan berdiskusi dan share informasi terkait perkembangan teknologi otomotif. Demikian juga dengan materi penggunaa alat ukur digital yang diperlukan untuk mengidentifikasi kerusakan pada mobil. Kegiatan ini menjadi dasar/pengantar bagi kegiatan praktikum yang akan dilakukan peserta.

3. Praktikum

Peserta akan diberikan materi tentang SOP pengoperasian alat dan bagaimana proses identifikasi kerusakan pada kendaraan. Pada sesi ini peserta sudah dibekali dengan job sheet untuk dapat mengamati setiap proses pada job sheet dengan detail. Setelah peserta leluasa mengamati proses pada sesi dimulai maka pada bagian ini peserta diberi kesempatan untuk mempraktikan sendiri materi yang sudah ada pada joobsheet tetap dengan pengawasan dan bimbingan instruktur. Pada bagian ini peserta dituntut untuk mengikuti setiap point pekerjaan guna menjamin kualitas pekerjaan.

4. Evaluasi

Setelah seluruh proses dilalui maka kegiatan ini diakhiri dengan proses evaluasi(Fernandez, Chandra, Maksum, \& Afnison, 2018). Langkah ini dilakukan untuk mengukur penguasaan peserta terkait materi yang diberikan. Skor pada proses evaluasi menjadi acuan ada/tidaknya peningkatan kemampuan peserta.

\section{HASIL DAN PEMBAHASAN}

Kegiatan PKM di SMK N 2 Payakumbuh dapat dibagi menjadi tiga tahapan yaitu: proses persiapan, pelaksanaan, evaluasi dan penutupan. Berikut detail dari tahapan tersebut:

\section{A. Proses Persiapan Kegiatan PKM}

\section{1) Survey Lokasi}

Kegiatan awal yang dilakukan adalah melakukan survey lokasi yang dilaksanakan di SMK N 2 Payakumbuh. Kegiatan ini dilakukan untuk mengetahui keadaan lokasi yang meliputi jarak tempuh, medan jalan dan lingkungan sekolah tempat dilaksanakannya program pengabdian. Pada tahap ini utusan tim pengabdian juga bertugas melakukan komunikasi dengan pihak sekolah dan pemetaan masalah terkait permasalahan PBM yang ada di SMK N 2 Payakumbuh terutama terkait mata pelajaran gambar teknik dan perancangan.

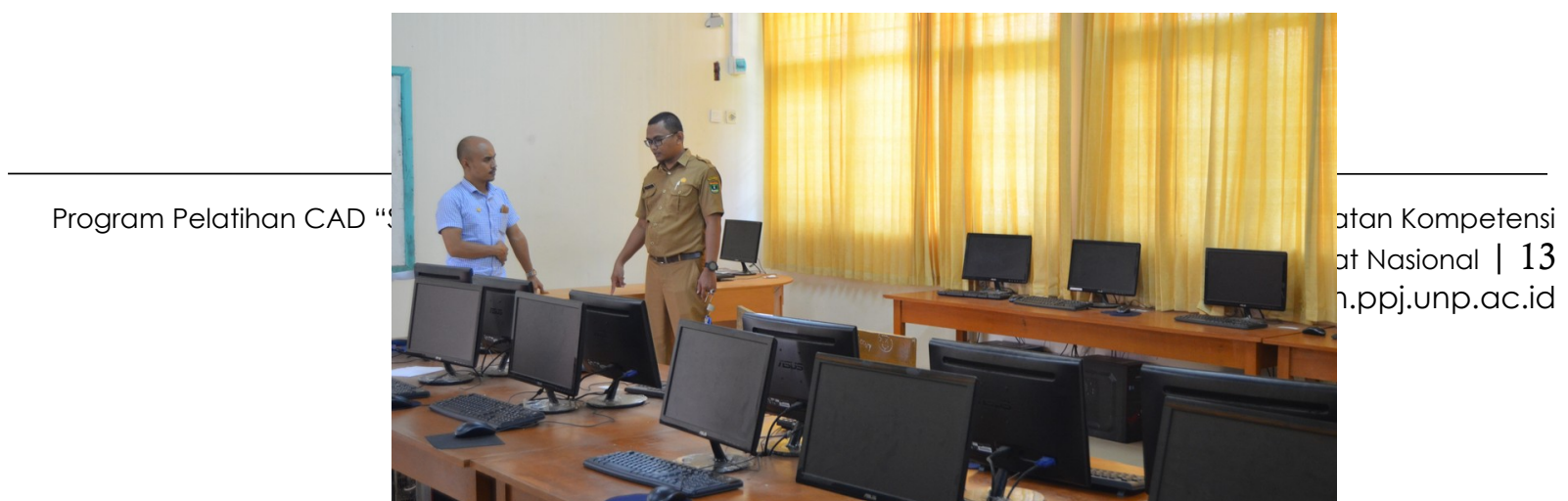


Gambar 3. Diskusi tim PKM di labor computer terkait teknis kegiatan

2) Pembuatan Kesepakatan Kerjasama Mitra

Setelah tim menemukan fakta permasalahan di lapangan kemudian tim berkoordinasi dengan pihak Sekolah terkait rencana pengabdian masyarakat. Alhamdulillah respon yang baik kami peroleh dari pihak Sekolah. Kepala Sekolah SMK N 2 Payakumbuh bersedia menjadi mitra kami dalam kegiatan Pengabdian Masyarakat.

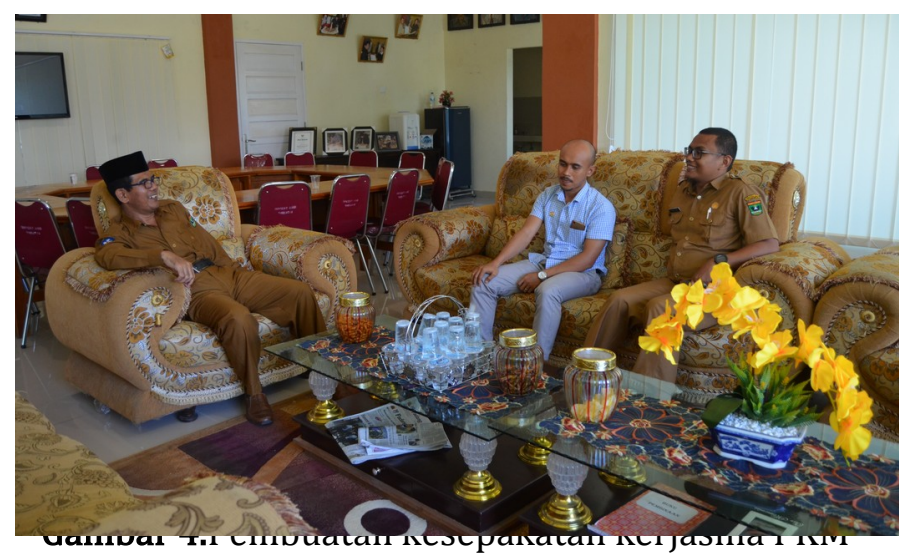

Selain kesepakatan kerjasama, juga disepakati jadwal dan agenda kegiatan.

Tabel 1. Agenda kegiatan

\begin{tabular}{cll}
\hline Pertemuan Ke & Materi Pelatihan & Metode \\
\hline I September & 1. Solidworks User Interface & Persentasi+ \\
2019 & a. Toolbar solidworks & praktik \\
& b. Display style & \\
& c. View orientation & \\
& d. Command manager & \\
& e. Mouse button & \\
& f. Solidworks model (templates) & \\
& 2. Pembuatan sketsa dan part modelling & \\
& a. 2D sketching & \\
& b. Smart dimension & \\
& c. Mates line & \\
3. Reference geometry &
\end{tabular}




\begin{tabular}{|c|c|c|}
\hline $\begin{array}{c}\text { II } \\
6 \text { September } \\
2019\end{array}$ & $\begin{array}{l}\text { 1. Solidworks Features } \\
\text { a. Revolved boss } \\
\text { b. Revolved cut } \\
\text { c. Swept boss } \\
\text { d. Swept cut } \\
\text { 2. Pattern } \\
\text { a. Linear pattern } \\
\text { b. Circular pattern } \\
\text { c. Table driven pattern } \\
\text { d. Curve driven pattern } \\
\text { 3. Editing and repair } \\
\text { 4. Configuration, equation and link }\end{array}$ & $\begin{array}{l}\text { Persentasi+ } \\
\text { praktik }\end{array}$ \\
\hline $\begin{array}{l}\text { III } \\
7 \text { September } \\
2019\end{array}$ & $\begin{array}{l}\text { 1. Solidworks assembly features } \\
\text { a. Guide rod assembly } \\
\text { b. Mate type } \\
\text { c. Modify component dimension } \\
\text { d. Smart mates } \\
\text { 2. Design library } \\
\text { 3. Tolerance and fit } \\
\text { 4. Folders and suppressed componen }\end{array}$ & $\begin{array}{l}\text { Persentasi+ } \\
\text { praktik }\end{array}$ \\
\hline $\begin{array}{l}\text { IV } \\
8 \text { September } \\
2019\end{array}$ & $\begin{array}{l}\text { EVALUASI } \\
\text { (Project desaian/perancangan } \\
\text { part/komponen lengkap dengan } \\
\text { analisa kekuatan material) }\end{array}$ & $\begin{array}{l}\text { Persentasi+ } \\
\text { praktik }\end{array}$ \\
\hline
\end{tabular}

\section{B. PROSES PELAKSANAAN KEGIATAN PKM}

a) Proses Keberangkatan Tim menuju Lokasi PKM

Tim PKM berangkat menuju lokasi satu hari menjelang kegiatan. Ini dilakukan karena tim PKM harus mengkondisikan labor computer terlebih dahulu jelang kegiatan. Tim didampingi mahasiswa melakukan instalasi aplikasi Solidworks di labor computer SMK N 2 Payakumbuh.

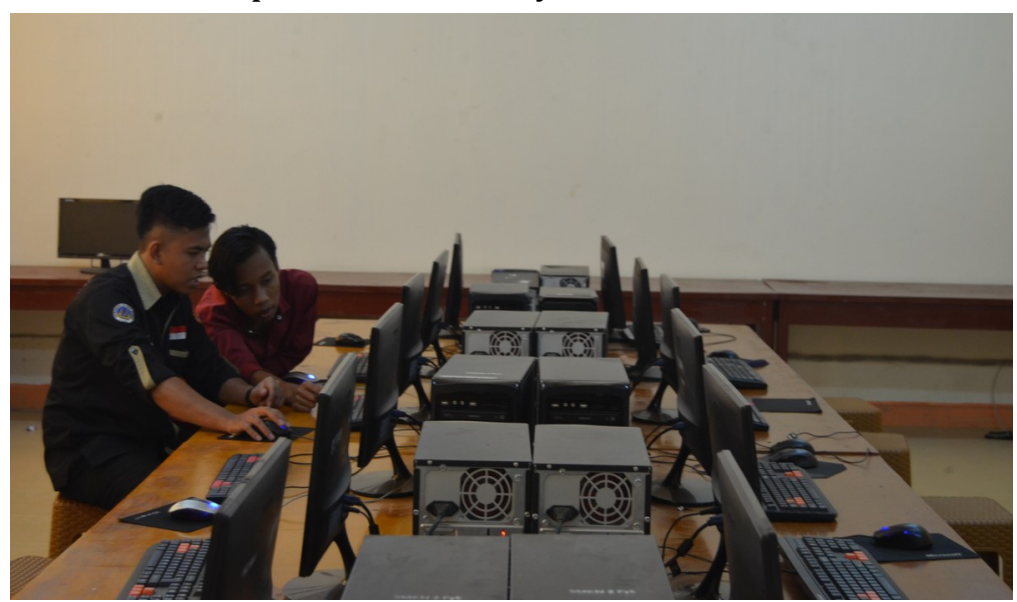

Gambar 5.Tim PKM dan mahasiswa melakukan instalasi software

b) Pembukaan Kegiatan PKM

Program Pelatihan CAD "SOLIDWORKS" Bagi Guru SMK N 2 Payakumbuh Sebagai Upaya Peningkatan Kompetensi dan Daya Saing SMK Daerah di Tingkat Nasional | 15 Available online: http://sulben.ppj.unp.ac.id 
Kegiatan PKM dilaksanakan pada tanggal 5-8 September 2019. Pembukaan kegiatan dilaksanakan di labor computer SMK N 2 Payakumbuh yang dihadiri oleh perwakilan Kepala Sekolah, tim PKM dan peserta pelatihan. Berikut dokumentasi kegiatan saat pembukaan kegiatan PKM.

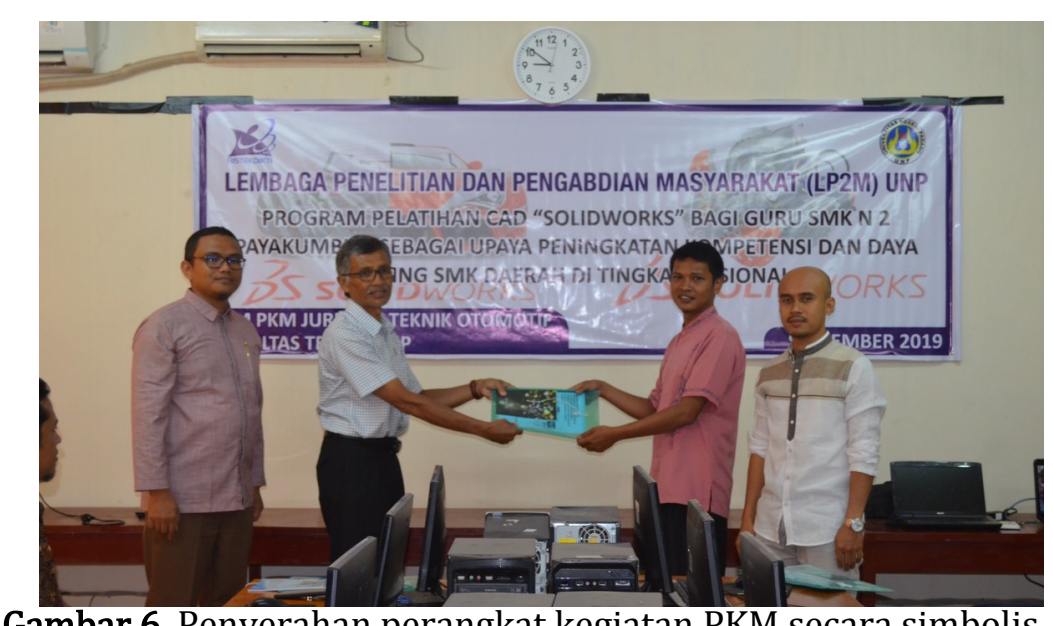

c) Pre test

Gambar 6. Penyerahan perangkat kegiatan PKM secara simbolis

Sebelum pelatihan dilaksanakan, kami dari Tim PKM melakukan test awal guna mengetahui sejauh mana penguasaan peserta terkait materi yang akan diberikan. Ini berfungsi segabai pemetaan awal sehingga menjadi acuan bagi Tim PKM untuk mempersiapkan materi dan metode yang sesuai agar kegiatan pelatihan dapat berjalan sebagaimana mestinya. Dari hasil pre test terlihat memang bahwa kemampuan peserta masih kurang terkait materi aplikasi desain CAD "solidworks". Berikut hasil pre test peserta PKM:

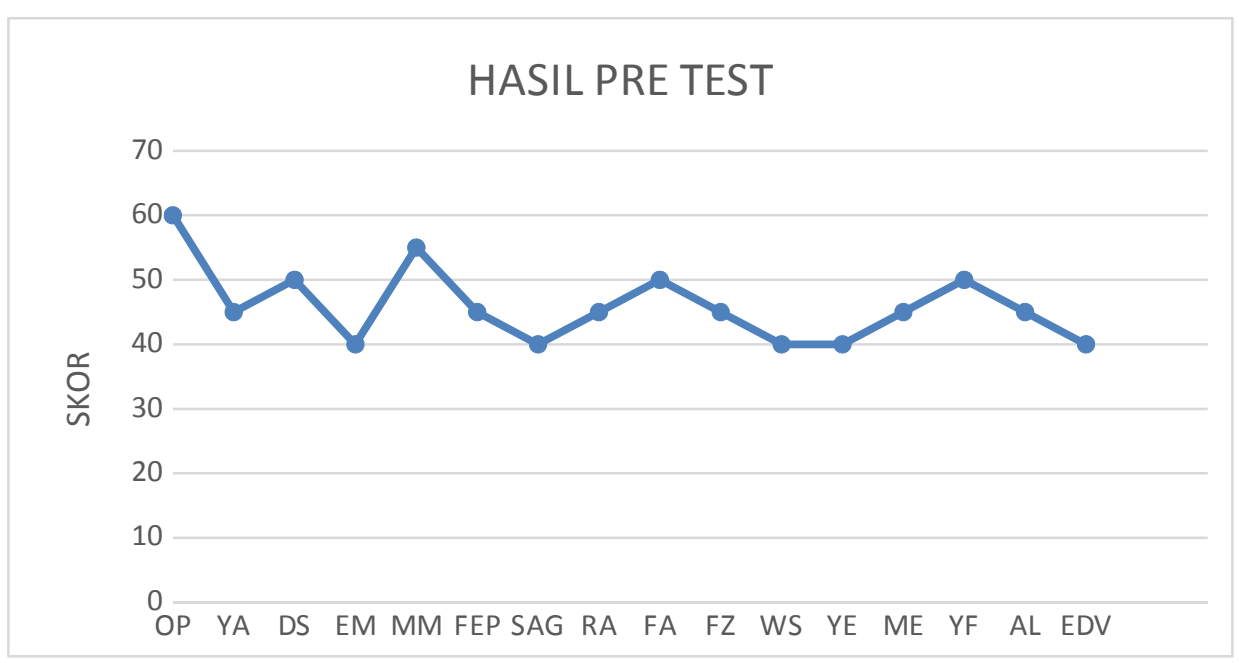

Gambar 7. Grafik hasil pre test peserta jelang kegiatan

d) Kegiatan inti 
Mengacu kepada hasil pre test, tim PKM merancang materi pelatihan yang mudah dipahami peserta. Materi disampaikan langsung dengan metode oral presentation dibantu dengan media power point yang memuat tahapan-tahapan pekerjaan perancangan dengan Solidworks. Mahasiswa pendamping kegiatan bertugas membantu dan memantau peserta jika mengalami kendala dalam melakukan praktik terkait materi yang diberikan.

Berikut dokumentasi selama kegiatan teori berlangsung yang bertempat di labor komputer SMK N 2 Payakumbuh :

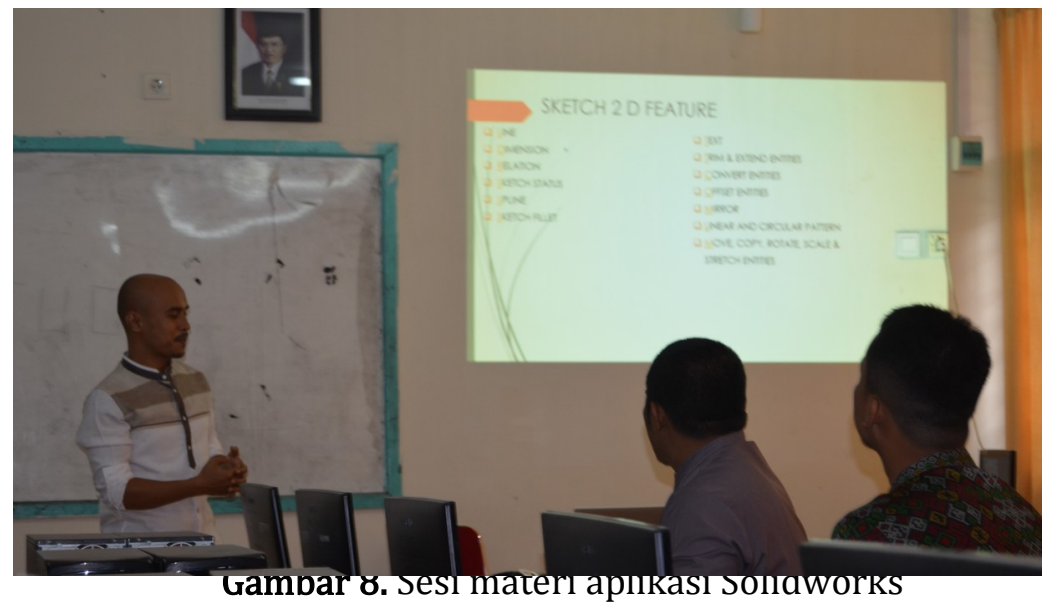

Setelah materi penggunaan solidworks disampaikan, peserta pelatihan mempraktikan secara langsung menggunakan computer masing-masing. Pada fase ini pemateri dibantu 2 orang mahasiswa untuk memfasilitasi peserta untuk mencobakan setiap materi yang diberikan.

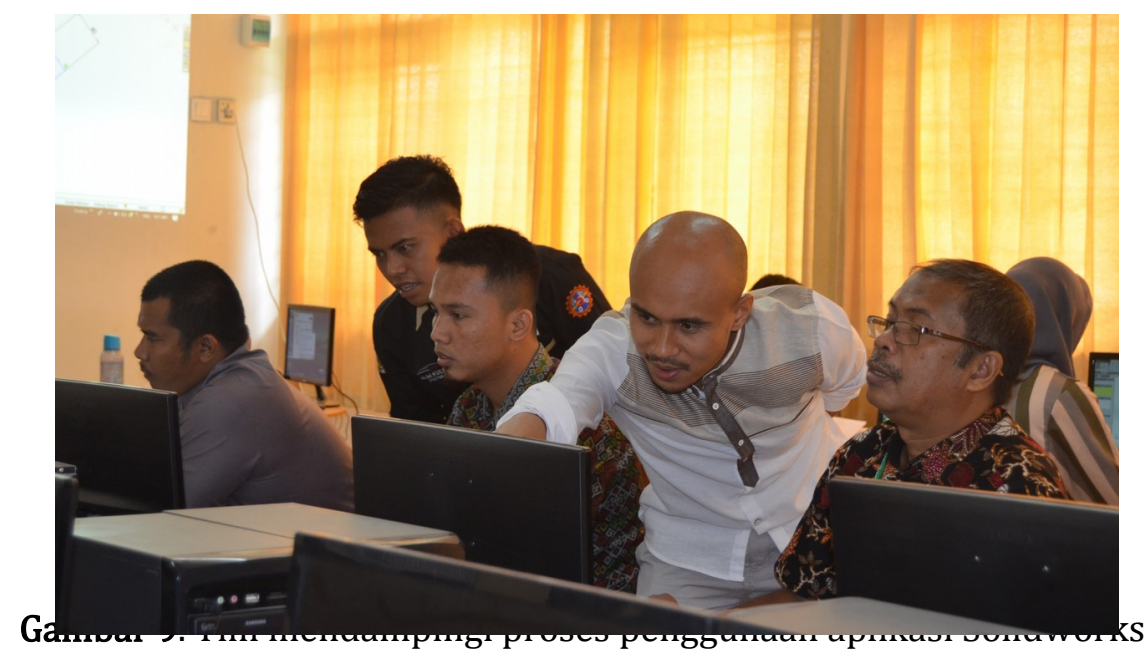

Pada setiap materi fitur solidworks yang diberikan, peserta diberi tugas kecil untuk membuat produk yang merupakan aplikasi dari fitur yang dipelajari. Hal ini membantu peserta untuk lebih cepat memahami bagaimana cara menggunakan aplikasi Solidwork.

Program Pelatihan CAD "SOLIDWORKS" Bagi Guru SMK N 2 Payakumbuh Sebagai Upaya Peningkatan Kompetensi dan Daya Saing SMK Daerah di Tingkat Nasional | 17 Available online: http://sulben.ppj.unp.ac.id 


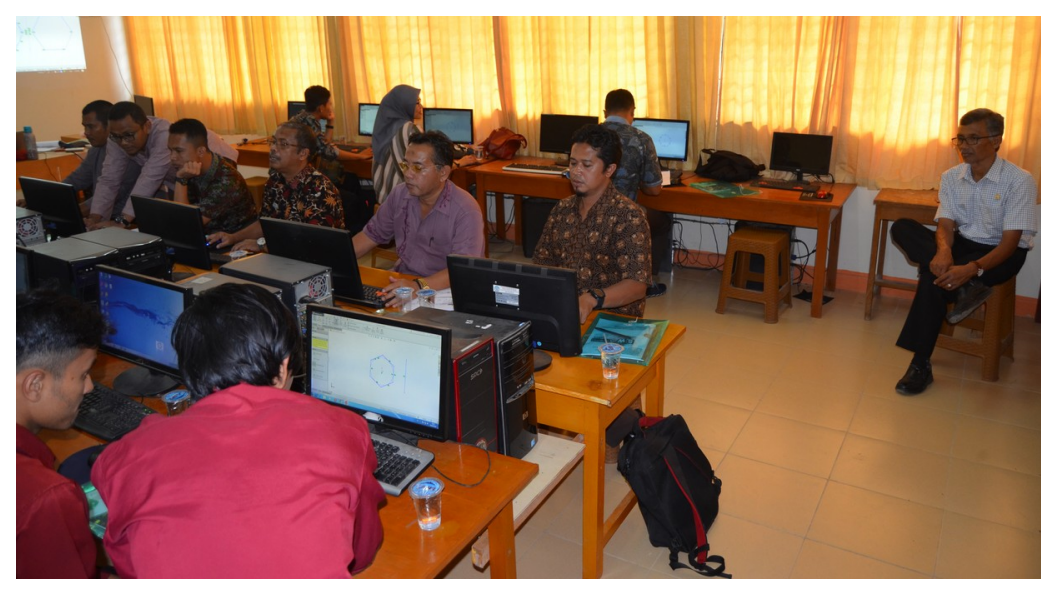

Gambar 10. Peserta membuat mini project pada setiap materi yang dipelajari.

\section{Evaluasi Kegiatan PKM}

Pada hari terakhir kegiatan, dilakukan evaluasi berupa pembuatan final project sebuah desain komponen otomotif. Peserta diberikan sebuah tugas untuk merancang salah satu komponen otomotif dimana ukurannya sesuai dengan ukuran aslinya. Pada kesempatan kali ini peserta diberi tugas merancang Shock Absorber sepeda motor. Berbagai kendala ditemui peserta lantaran untuk merancang subuah komponen yang meliputi assembly itu membutuhkan ukuran yang akurat dan pesisi, jika tidak maka sulit untuk dilakukan assembly part.

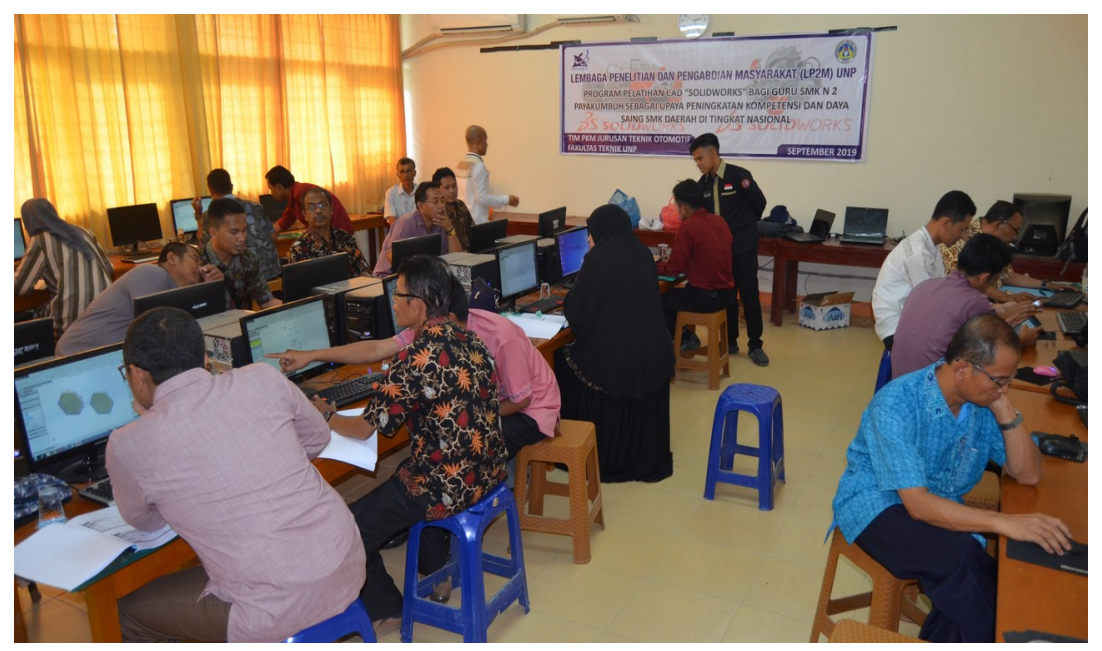

Gambar 11. Evaluasi kegiatan 
Berikut salah satu Shock Absorber hasil rancangan peserta pelatihan.

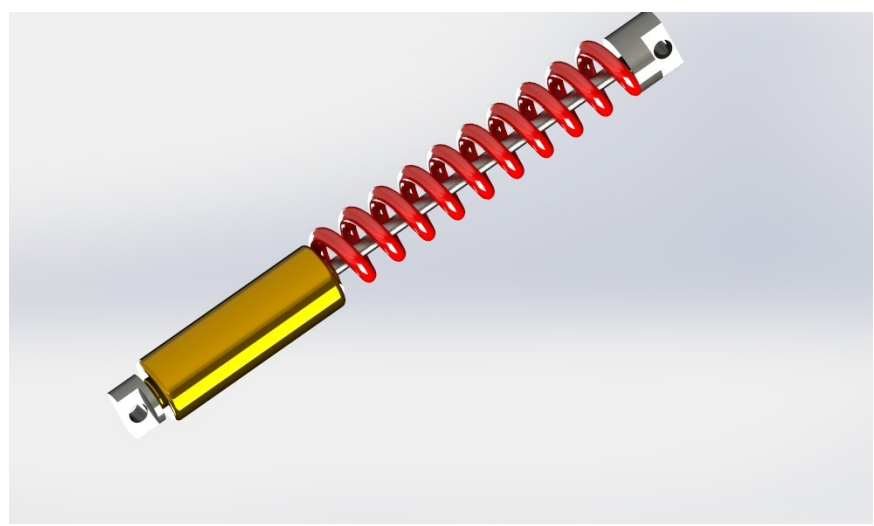

Gambar 12. Final project salah seorang peserta

Berikut hasil rekap evaluasi kegiatan di akhir acara yang mengacu kepada final project peserta.

\section{GRAFIK PENINGKATAN PEMAHAMAN PESERTA TERKAIT PENGGUNAAN APLIKASI SOLIDWORKS}

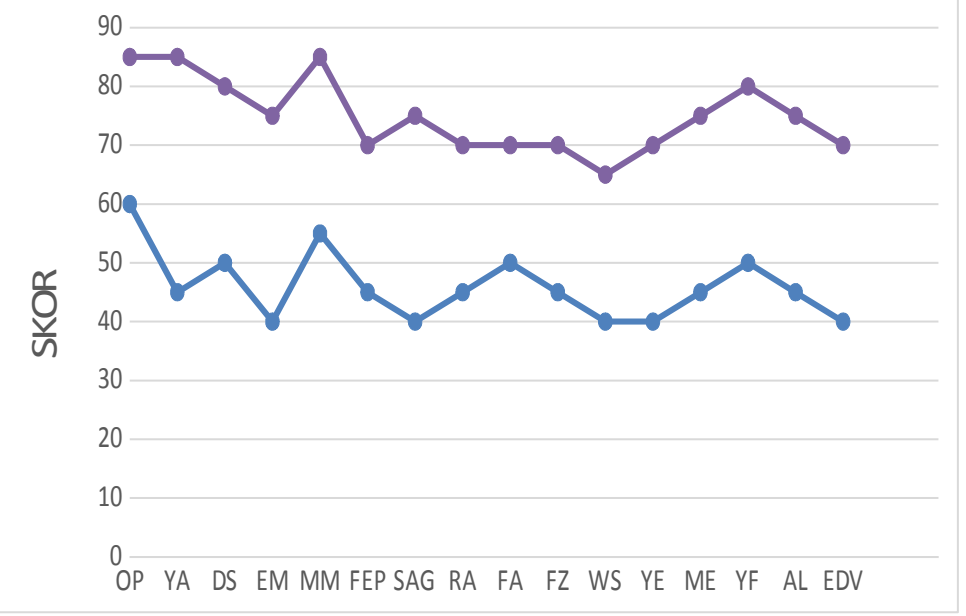

Gambar 13. Grafik Peningkatan pemahaman peserta sebelum dan pasca kegiatan

\section{Kegiatan Penutup}

Penutupan kegiatan dilaksanakan tepat setelah selesainya sesi evaluasi (pembuatan final project). Pada pidatonya, kepala sekolah yang diwakili waka humas menyatakan terimakasih atas adanya pelatihan ini dan berharap agar pelatihan ini dilanjutkan lagi kedepannya mengingat aplikasi desain komponen mesin ini sangat bermanfaat bagi peserta didik nantinya. Hal senada juga disampaikan oleh salah seorang peserta yang mengatakan bahwa menggunakan aplikasi Solidworks lebih mudah dan menarik. Mereka berharap ada pelatihan lanj

Program Pelatihan

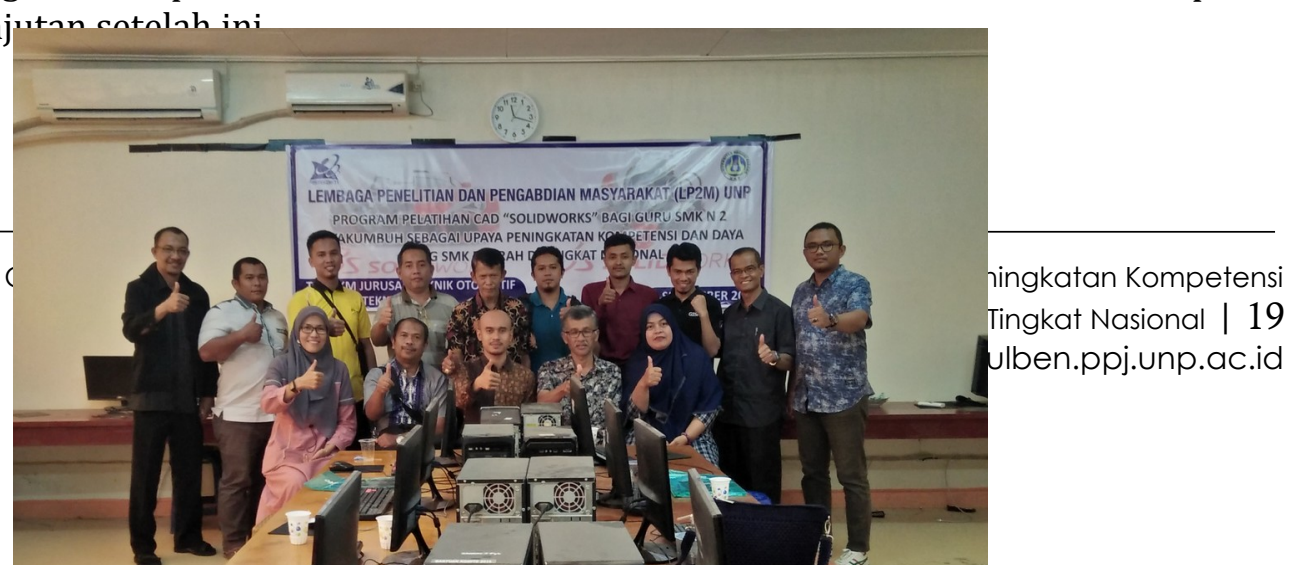


Gambar 13. Sesi foto bersama di akhir kegiatan PKM

\section{KESIMPULAN}

Dari kegiatan PKM(Penyusun, Penelitian, Pengabdian, Masyarakat, \& Masyarakat, 2019) yang berlangsung selama 4 hari di SMK N 2 Payakumbuh sangat terlihat antusiasme peserta dalam melaksanakan kegiatan. Tingginya antusiasme peserta pelatihan menandakan bahwa materi yang diberikan itu cukup menarik dan sesuai dengan yang dibutuhkan peserta. Pihak kepala sekolah juga menunjukan antusias yang tinggi dalam menyikapi kegiatan pelatihan ini. Pihak sekolah menyatakan kesiapannya untuk kembali menjadi mitra PKM pada tahun berikutnya. Selain itu pihak sekolah juga berjanji akan mengagendakan pelatihan mandiri penggunaan solideworks ini secara mandiri dengan mendatangkan pemateri PKM saat ini.

Berdasarkan fakta yang disebutkan diatas, penulis dapat mengambil kesimpulan bahwa ketepatan materi pelatihan dan kebutuhan peserta menjadi kunci suksesnya sebuah agenda PKM. Penulis yakin jika peserta secara konsistem menggali dan mengembangkan materi pasca pelatihan, bukanlah hal yang mustahil bagi SMK N 2 Payakumbuh untuk mampu sejajar dengan SMK di luar sumatera.

\section{DAFTAR PUSTAKA}

Erzeddin Alwi, Nuzul Hidayat, Wanda Afnison, D. Y. (2018). PROGRAM UP-GRADE SKILL SERVICE SEPEDA MOTOR BAGI MEKANIK BENGKEL PEMULA. PAKAR PENDIDIKAN. VOL. 16 NO. 1 JANUARI 2018 (16-21), VOL 16, 16-21.

Fernandez, D., Chandra, R., Maksum, H., \& Afnison, W. (2018). WORKSHOP PENYUSUNAN PENELITIAN TINDAKAN KELAS (PTK). (4).

Hidayat, N., Arif, A., Setiawan, M. Y., \& Afnison, W. (2018). Peningkatan Pengetahuan dan Keterampilan Pemuda Putus Sekolah Melalui Pelatihan Perawatan Berkala Sepeda Motor. INVOTEK: Jurnal Inovasi Vokasional Dan Teknologi, 18(2), 83-90. https://doi.org/10.24036/invotek.v18i2.360

Penyusun, T., Penelitian, L., Pengabdian, D. A. N., Masyarakat, K., \& Masyarakat, K. (2019). Pelaksanaan pengabdian kepada masyarakat. 